INT'L. J. PSYCHIATRY IN MEDICINE, Vol. 36(4) 401-412, 2006

\title{
THE ACCURATE DIAGNOSIS OF EARLY-ONSET DEMENTIA
}

MARIO F. MENDEZ, MD, PH.D.

University of California at Los Angeles (UCLA);

and V.A. Greater Los Angeles Healthcare System

\begin{abstract}
Early-onset dementia (EOD, $<65$ years at onset) is a relatively common and frequently misdiagnosed condition. One reason for misdiagnosis is that EOD has a more varied differential diagnosis than late-onset dementia (LOD). For example, Alzheimer's disease (AD), the preponderant LOD, makes up only about one-third of EODs; the rest are due to vascular dementias, frontotemporal lobar degenerations, traumatic head injury, alcohol-related dementia, and a great many other conditions. Another reason for misdiagnosis is that early-onset $\mathrm{AD}$ may have predominant cognitive deficits other than memory loss and a potential familial inheritance with spastic paraparesis, seizures, or myoclonus. A third reason is that EOD often presents with neuropsychiatric features out-of-proportion to any cognitive deficits. Despite these obstacles, it is important to accurately diagnose EODs, particularly because they differ in management and course. Clinicians can successfully diagnose most EODs with careful cognitive and family histories, mental status and neurological examinations, and neuroimaging.

(Int'l. J. Psychiatry in Medicine 2006;36:401-412)
\end{abstract}

Key Words: dementia, Alzheimer's disease, vascular dementia, frontotemporal dementia, traumatic brain injury 


\section{INTRODUCTION}

Early-onset dementia (EOD) is an important and poorly understood diagnostic category. Investigators, however, have relatively ignored EOD while focusing on late-onset dementia (LOD) $[1,2]$. This is unfortunate because EOD can have particularly devastating psychosocial consequences as it afflicts people who are often in their most productive years and supporting families [1-4]. Moreover, EOD is more of a problem and more common than previously realized. Recent clinical reports indicate a significant proportion of EOD patients compared to LOD patients $[1,4,5]$. Among 948 U.S. veterans, $278(30 \%)$ had EOD [1], and, among 619 patients in England, the proportion of patients with EOD was $28.6 \%$ [4]. In another report of 311 patients in Brazil, the proportion of patients with EOD was a high of 46.6\% [5]. These studies indicate that there are significant proportions of patients with EOD at least among select populations.

EOD is a somewhat arbitrary and poorly understood category of dementia. The definition of EOD is based on a traditional and historical cut-off of dementia with age of onset of less than 65 years [1,2]. Although this separation is artificial, it is still used in discussing patients with dementia. For example, the World Health Organization continues to distinguish between "dementia in Alzheimer's disease with early onset before age of 65" vs. "dementia in Alzheimer's disease with late onset" [6]. The overall prevalence of EOD is low compared to LOD, but still considerable [5, 7-9]. The prevalence of EOD is about 67 to 81 per 100,000 persons in the 45 to 65 year old age group with exponential increases beginning at age $35[4,10-13]$. The incidence of EOD is about 8.3 new cases per year per 100,000 persons in the 50-64 age range [14].

\section{THE MISDIAGNOSIS OF EOD}

Despite the importance, clinicians misdiagnose many if not most patients with EOD early in their course [2, 5, 10, 15-17]. Although clinical criteria exist for the most common EODs, misdiagnosis is common even at tertiary centers [2]. Clinicopathologic studies report a wide range (0-71\%) of clinical accuracy for diagnosing VaD and FTD $[13,15,18,19]$. During the first few years of their disease, these patients may see many different doctors and undergo extensive medical evaluations with significant delays in diagnosis of 3-4 years or more $[17,18]$. Yet, the accurate diagnosis of EODs has management consequences $[2,20]$. For example, patients with early-onset AD may respond to acetylcholinesterase inhibitors; however, those with frontotemporal dementia (FTD) may worsen with these medications [21]. A range of specific drugs continue to be tried for $\mathrm{VaD}$ including nimodipine, propentofylline, vinpocetine, and pentoxifylline [22]. Infectious and toxic-metabolic causes of EOD have their own treatments. Furthermore, EODs may require different attention to potential genetic factors or additional diagnostic measures, such as a search for rarer vasculopathies (see Figure 1). 
DIAGNOSING EARLY-ONSET DEMENTIA / 403
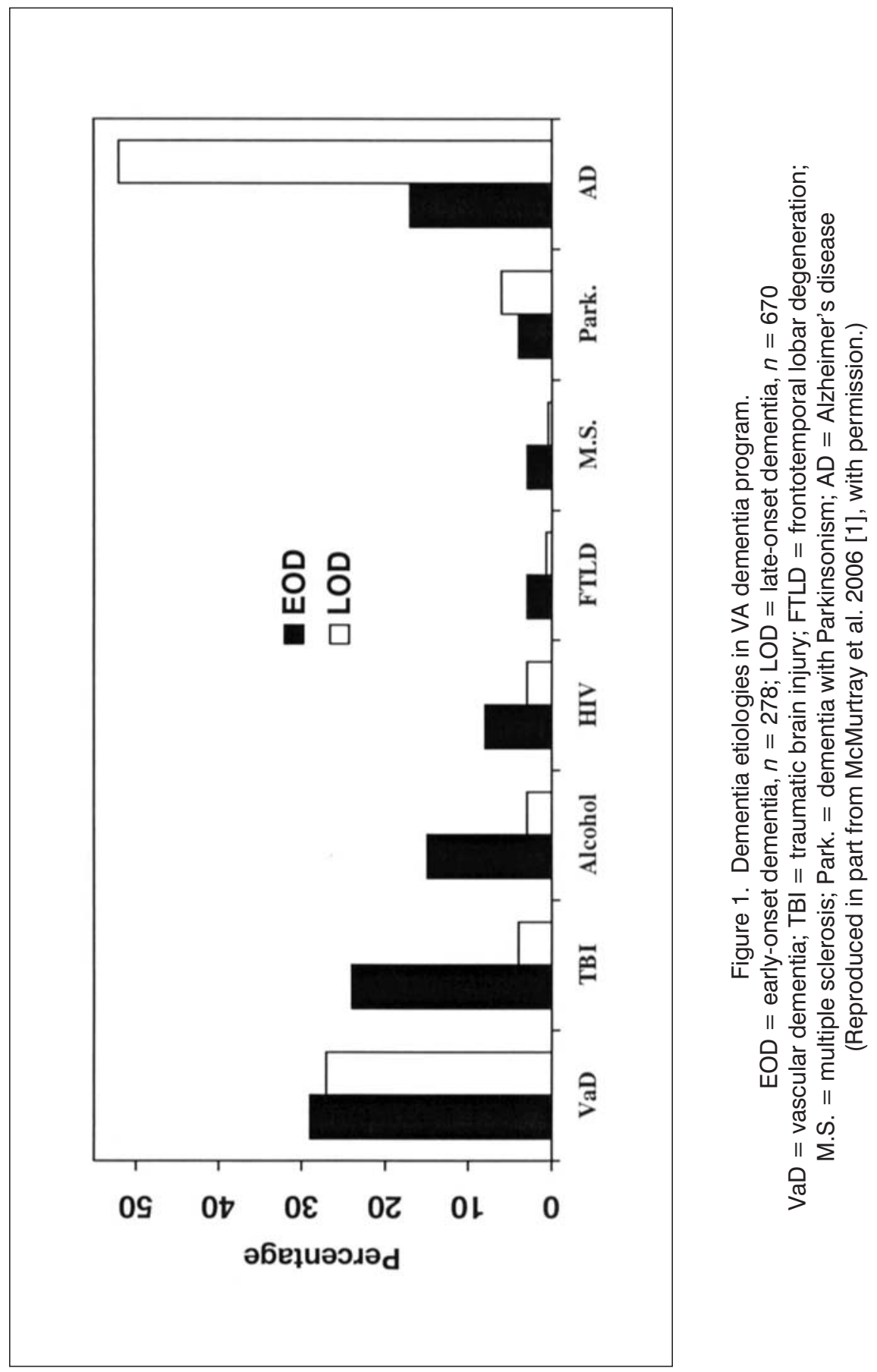


\section{Clinical Case Example of Misdiagnosis}

A 42-year-old woman presented for neurological assessment because of a 3 -year history of personality change [23]. She had become detached and disengaged from her work, family, and usual activities. Her personal hygiene had declined, and she followed exactly the same routines every day. The patient began eating more and gained a significant amount of weight. Went asked, she stated that nothing was really wrong with her but that certain people were trying to hurt her. Her psychiatrist diagnosed her with major depression with paranoid features until it became clear that she was progressively worsening.

On examination, she had little spontaneous behavior or emotional expression. Mental status assessment revealed deficits in memory, visuospatial skills, and frontal-executive functions. Her neurological examination and routine laboratory data was otherwise normal, and her MRI revealing generalized cerebral atrophy. This time the patient was misdiagnosed as having FTD [24]. After yet another year of continued decline, a positron emission tomography (PET) study showed significant hypometabolism in prefrontal, parietal, and temporal cortex bilaterally and genetic testing revealed the presence of a presenilin-1 mutation for autosomal dominant $\mathrm{AD}$. The patient did not have a known family history for this disorder but information on her father was lacking. Once correctly diagnosed, appropriate management was initiated including a further investigation of her family history and genetic counseling.

\section{High Proportion of Non-AD Dementias}

There are several reasons for the misdiagnosis of EOD. One reason is that patients with EOD are more likely than those with LOD to have dementias other than $\mathrm{AD}$ (see Figure 1) [2, 14, 20]. Although $\mathrm{AD}$ is the most frequent etiology of dementia [2], it account for only about one third of all those with an early age onset, compared to about two thirds (50-75\%) of LODs [4, 9, 25-27]. The other common EODs are vascular dementia (VaD), FTD and related disorders, sequelae from traumatic brain injury (TBI), and alcohol-related dementia $[1,4,5,14,20]$. $\mathrm{VaD}$ is more common in $\mathrm{EOD}$ than in late-onset disease $[4,25,28]$, and, in a few reports, $\mathrm{VaD}$ is the most prevalent EOD $[1,5,26]$. Similarly, FTD is much more common in EOD than in late onset disease [28], and, in a few reports, FTD is as prevalent as AD among EODs [13, 28]. TBI and alcohol are common causes of dementia in the young but vary with specific population groups (see Table 1).

In several series $[1,5,26]$, VaD was the most important and common cause of dementia in the presenium. There are problems in the diagnosis of clinical VaD. The major clinical criteria for $\mathrm{VaD}$ and other vascular dementias overlap in $<50 \%$ of cases [22,29], and patients with $\mathrm{VaD}$ often lack a history of stroke, an abrupt or stepwise decline in cognition, focal neurological signs, or a clear relationship of magnetic resonance imaging (MRI) changes to cognition $[22,30]$. In contrast, a pleurality, if not the majority, of patients with $\mathrm{VaD}$ have subcortical ischemic 
DIAGNOSING EARLY-ONSET DEMENTIA / 405

Table 1. Comparison of Percentages of EOD in Different Studies

\begin{tabular}{|c|c|c|c|c|c|c|}
\hline Diagnosis & $\begin{array}{c}\text { England } \\
n=185 \\
{[4]}\end{array}$ & $\begin{array}{c}\text { Australia } \\
n=150 \\
{[18]}\end{array}$ & $\begin{array}{c}\text { Scotland } \\
n=114 \\
{[17]}\end{array}$ & $\begin{array}{c}\text { Brazil } \\
n=141 \\
{[5]}\end{array}$ & $\begin{array}{c}\text { Japan } \\
n=34 \\
{[20]}\end{array}$ & $\begin{array}{c}\text { United } \\
\text { States } \\
n=278 \\
{[1]}\end{array}$ \\
\hline$A D^{a}$ & $65(35.1 \%)$ & 32 (21.\%) & $60(52.6 \%)$ & $30(21.3 \%)$ & $15(44.1 \%)$ & 48 (17\%) \\
\hline $\operatorname{VaD}\left(1^{\circ} \mathrm{SIVD}\right)$ & $34(18.4 \%)$ & 38 (25\%) & 13 (11.4\%) & $52(36.9 \%)$ & $8(23.5 \%)$ & 80 (29\%) \\
\hline FTLD ( $1^{\circ}$ FTD $)$ & $23(12.4 \%)$ & $36(24 \%)$ & NR & $7 \quad(5 \%)$ & 5 (14.7\%) & $11(4 \%)^{C}$ \\
\hline Parkinsonian ${ }^{b}$ & 16 (8.5\%) & NR & NR & $5 \quad(3.5 \%)$ & 1 (2.9\%) & 9 (3.2\%) \\
\hline Huntington's & 9 (4.9\%) & NR & NR & NR & 0 & $4(1 \%)$ \\
\hline TBI & NR & NR & NR & 13 (9.2\%) & 3 (8.8\%) & 67 (24\%) \\
\hline Alcohol-related & 19 (10.3\%) & 3 (2\%) & $14(12.3 \%)$ & $7 \quad(5 \%)$ & 0 & $15(5 \%)$ \\
\hline Other ${ }^{d}$ & 19 (10.2\%) & 41 (27\%) & 27 (23.7\%) & 27 (19.1\%) & 2 (5.9\%) & 44 (15.8\%) \\
\hline
\end{tabular}

${ }^{a}$ Probable and possible AD. ${ }^{b}$ Parkinsonism disorders include dementia with Lewy bodies. ${ }^{c}$ Numbers include a few patients reclassified from original paper. FTD artificially low because of mental health clinic presentation, rather than to "memory" clinics. NR $=$ Not Reported. ${ }^{d}$ Other: Infections, toxic-medical conditions, normal pressure hydrocephalus, multiple sclerosis.

disease composed of pre-infarction white matter changes (leukoaraiosis) and lacunar strokes on MRI [28, 29, 31, 32]. These changes can be associated with an insidious and gradually progressive dementia as the ischemic burden accumulates [29-31]. Structural imaging with MRI can be helpful; however, the presence of subcortical ischemic vascular changes may not be the cause of the clinical dementia; many of these patients have mixed Alzheimer-vascular dementia [29, 33-36]. In sum, the most common form of $\mathrm{VaD}$ has at least two strategically placed subcortical lacunes plus at least a moderate amount of leukoaraiosis on MRI.

FTD is the third most common EOD in most series, and one that typically presents in the fifties or earlier. Like AD, FTD is an insidious and progressive neurodegenerative dementia without overt neurological signs. The early diagnosis of FTD is difficult and relies on the detection of alterations in social interpersonal behavior, abnormalities in personal regulation, emotional blunting, and loss of insight [24]. Many of these patients have subtle behavioral changes of a socioemotional nature which can dominate the cognitive examination and obscure the diagnosis of an EOD [15, 24, 37]. Routine clinical MRI usually does not distinguish AD from FTD [24], and investigators have not established a reliable biological marker that can help discriminate between these dementias. Patients with FTD, however, have frontal, anterior temporal, or frontotemporal hypometabolism or hypoperfusion on functional neuroimaging and usually meet diagnostic criteria after a period of follow-up. 
TBI is an important cause of EOD. In some series, dementia from TBI comprises $9-24 \%$ of EODs $[1,5,28]$. Since TBI is the most common cause of neurologic illness in young people, it is not surprising that it is a significant cause of chronic deficits in cognition. The vast majority of TBIs are nonpenetrating and result from motor vehicle accidents (50\%), falls $(21 \%)$, violence $(12 \%)$, and sports or recreational injuries (10\%) [2]. Diffuse, non-penetrating TBI often results in permanent neurobehavioral deficits in information processing speed and motor slowing, attention and concentration, memory, and frontalexecutive functions [2]. The most common and severe focal TBI effects result from bilateral injuries to the basolateral frontal cortex and the temporal lobes. Furthermore, TBI is a risk factor for the eventual development of AD [2].

EOD can be a consequence of chronic alcohol abuse [4, 20]. Alcohol-related dementia is more common in younger people than in old people [4, 38]. For example, alcohol-related dementia occurred in $12 \%$ of one series of EOD patients from England [4]. This entity is hetereogeneous and includes disturbances in executive functions and autobiographical memory as well as the clinical features of vitamin deficiency states such as Wernicke-Korsakoff's syndrome [2]. Moreover, drug and alcohol abuse often occur together, and their effects may be difficult to disentangle. Clinicians should always evaluate the presence of alcohol or other drug abuse as potential etiological factors for a cognitive decline in young people.

The differential diagnosis of EOD also includes a range of other conditions (see Table 2). Most of these are infections, toxic-metabolic, or inheritable conditions. Infectious dementias include Creutzfeldt-Jakob Disease and other prion disorders, HIV-associated dementia, and the residual of encephalitides. Familial prion disorders may have a chronic progressive course, particularly if due to an insertional mutation. Toxic-metabolic disturbances, such as hepatic failure or sleep apnea, can have a chronic course and present with dementia. Inheritable disorders range from Huntington's disease (HD) to a number of inborn errors of metabolism that can occur in adulthood. The differential diagnosis of EOD includes a number of miscellaneous conditions such as normal pressure hydrocephalus (NPH), epilepsy, multiple sclerosis, and neoplastic-related conditions. Finally, additional neurodegenerative disorders should be considered. These include Parkinsonian disorders with dementia especially Parkinson's disease dementia, dementia with Lewy bodies, progressive supranuclear palsy, and corticobasal degeneration [4, 20,39].

\section{Differences between Early-Onset AD vs. Late-Onset AD}

Another reason for the misdiagnosis of EOD is the potential clinical differences between early-onset $\mathrm{AD}$ and late-onset $\mathrm{AD}[1,4]$. The traditional model of $\mathrm{AD}$ is the late-onset disorder characterized by prominent memory difficulty and word-finding problems. Early reports, however, considered sporadic early-onset 
Table 2. Common Early-Onset Dementias

\begin{tabular}{|c|c|}
\hline Neurodegenerative Disorders & Toxic-Metabolic Disorders \\
\hline Alzheimer's disease and variants & Alcohol and other substance abuse \\
\hline $\begin{array}{l}\text { Frontotemporal dementia and } \\
\text { variants }\end{array}$ & $\begin{array}{l}\text { Heavy metals, organophosphates, } \\
\text { toxins }\end{array}$ \\
\hline Dementias with Parkinsonism & Sleep apnea \\
\hline Huntington's and Wilson's disease & Anoxic and Hypoglycemia \\
\hline Spinocerebellar Ataxias & Gastrointestinal, hepatic \\
\hline $\begin{array}{l}\text { Dementia with motor neuron or } \\
\text { muscle disease }\end{array}$ & $\begin{array}{l}\text { encephalopathy } \\
\text { Renal failure and dialysis dementia }\end{array}$ \\
\hline Vascular Disorders & $\begin{array}{l}\mathrm{B}_{12} \text {, thiamine, folate, niacin } \\
\text { deficiencies }\end{array}$ \\
\hline $\begin{array}{l}\text { Strategic subcortical strokes } \pm \\
\text { leukoaraiosis }\end{array}$ & $\begin{array}{l}\text { Thyroid, parathyroid, adrenal, } \\
\text { pituitary }\end{array}$ \\
\hline $\begin{array}{l}\text { Binswanger's disease (severe } \\
\text { leukoaraiosis) }\end{array}$ & Adult Inborn Errors of Metabolism \\
\hline Inherited vasculopathies & Leukodystrophies. \\
\hline $\begin{array}{l}\text { CNS vasculitides, e.g., Sneddon, } \\
\text { Susac, etc. }\end{array}$ & $\begin{array}{l}\text { Polioencephalopathies, e.g., Fabry, } \\
\text { Kuf, etc. }\end{array}$ \\
\hline & Porphyria \\
\hline Infectious Disorders & \\
\hline HIV-associated dementia & Miscellaneous \\
\hline $\begin{array}{l}\text { Creutzfeldt-Jakob disease and } \\
\text { other prions }\end{array}$ & $\begin{array}{l}\text { Traumatic brain injury, dementia } \\
\text { pugilistica }\end{array}$ \\
\hline Neurosyphilis & Normal pressure hydrocephalus \\
\hline Lyme disease & Hashimoto's encephalopathy \\
\hline Chronic fungal meningitis & Epilepsy-related \\
\hline Whipple's disease & Neoplastic or paraneoplastic \\
\hline Post-encephalitis & Multiple sclerosis \\
\hline Subacute sclerosing & CNS sarcoidosis \\
\hline panencephalitis & Psychiatric diseases especially \\
\hline $\begin{array}{l}\text { Progressive multifocal } \\
\text { leukoencephalopathy }\end{array}$ & depression \\
\hline
\end{tabular}


$\mathrm{AD}$ and late-onset $\mathrm{AD}$ to be separate diseases based on greater cortical deficits and greater parietal involvement in early-onset AD [40]. Some found a higher prevalence of language impairment and a faster progression in early-onset $\mathrm{AD}$ vs. late-onset $\mathrm{AD}$ [41-43], but others failed to find these differences [40, 41]. Extensive neuropsychological testing, however, has indicated that cortical visuospatial functions are more impaired in early-onset $\mathrm{AD}$ vs. late onset disease, including embedded figure perception, hand-eye coordination, block design, and visual reproduction $[40,44]$. Consistent with these neuropsychological findings, positron emission tomography (PET) scans and neuropathology suggest more severe deficits in parietal areas in early-onset $\mathrm{AD}$ vs. late-onset $\mathrm{AD}$ [2, 45-47]. Furthermore, clinicians need to recognize patients with early-onset AD that might have an autosomal dominant frontal disorder as illustrated by the Clinical Case Example [23, 48]. Distinct from the usual sporadic early-onset AD, the rare patients with presenilin 1 or other mutations can develop paraparesis, seizures, and myoclonus, in addition to a frontally predominant disorder resembling FTD $[23,49]$. It is important to recognize these genetic variants so that clinicians and families can consider genetic testing and counseling.

\section{Presentation with Neuropsychiatric Symptoms}

A further source of misdiagnosis is the presentation of EOD with neuropsychiatric symptoms. Several EODs can present with a wide variety of subtle behavioral, cognitive, psychiatric, or neurological symptoms. FTD in particular, results in personality changes, including alterations in social-emotional behavior, insight, and personal regulation, changes in oral behavior, and repetitive, compulsive acts. Some of these patients have even presented with sociopathic acts [50]. Other neuropsychiatric presentations of EODs include apathy or abulia with $\mathrm{VaD}$, intermittent explosive disorder and poor judgment with TBI, depression or disinhibition with HD, and psychosis or anxiety with Hashimoto's encephalopathy. The clinician needs a high index of suspicion for EOD when patients develop new onset psychiatric symptoms in mid-life.

\section{THE EFFECTIVE DIAGNOSIS OF EODs}

Given these sources of misdiagnosis, what can clinicians do to effectively diagnose EODs? The accurate diagnosis of most of these disorders is possible with a series of systematic steps. First, obtain a good clinical history and course. Determine if there has been a change from a prior level of functioning and whether there are cognitive deficits, behavioral or neuropsychiatric features, or both. Second, evaluate for dementia risk factors. These include a history of TBI with coma or significant post-traumatic amnesia and a history of alcohol and drug abuse. Third, determine if there is a positive family history for dementia. In particular, evaluate for autosomal dominant disorders among first-degree 
relatives. Fourth, perform a thorough neurological examination. The additional features of pyramidal, extrapyramidal, cerebellar, or peripheral nerve involvement are key diagnostic clues in this group and help to direct investigations. Fifth, obtain an MRI. The presence of white matter changes is particularly useful in evaluating for vascular disease or leukodystrophies. Finally, obtain special tests as needed. Useful studies are lumbar puncture for infectious processes, diffusionweighted MRI for prion disease, and positron emission tomography for FTD. Together, these steps should facilitate the accurate diagnosis of most patients with EOD.

\section{CONCLUSIONS}

Patients with EODs are not rare, and most psychiatrists and neurologists are likely to be faced with one of these patients. EODs have a broader differential diagnosis than LOD. AD, the preponderant dementia in late life, makes up only about a third of EODs and often differs in having more visuospatial deficits than memory loss and a greater risk of familial inheritance. Compared to LOD, a greater proportion of EODs have $\mathrm{VaD}$, FTD and related syndromes, dementia due to TBI, alcohol-related dementia, and other conditions. Moreover, compared to LOD, EODs are more likely to present with neuropsychiatric features. Careful attention to cognitive and family history, mental status and neurological examinations, and neuroimaging can differentiate most EODs as long as clinicians have a high index of suspicion. More research needs to clarify methods to diagnose these entities because they have different managements and are increasingly likely to have targeted treatments in the future.

\section{REFERENCES}

1. McMurtray A, Christine D, Clark D, Farag E, Mendez M. Early onset dementia: Frequency and causes in comparison to late onset dementia. Dementia Geriatric Cognizant Disease 2006;21:59-64.

2. Mendez MF, Cummings JL. Dementia. A clinical approach (3rd ed). New York: Elsevier, 2003.

3. Delaney N, Rosenvinge H. Presenile dementia: Suffers, careers and services. International Journal of Geriatric Psychiatry 1995;10:597-601.

4. Harvey RJ, Skelton-Robinson M, Rossor MN. The prevalence and causes of dementia in people under the age of 65 years. Journal of Neurology, Neurosurgery and Psychiatry 2003;74:1206-1209.

5. Fujihara S, Brucki SM, Rocha MS, Carvalho AA, Picccolo AC. Prevalence of presenile dementia in a tertiary outpatient clinic. Arq Neuropsiquiatr 2004; 62:592-595.

6. International Classification of Diseases-10th Revision (ICD-10). Geneva: World Health Organization, 1992. 
7. McGonigal, G, Thomas B, McQuade C, Starr JM, Whalley LJ. Epidemiology of Alzheimer's presenile dementia in Scotland, 1974-88. British Medical Journal 1993;306:680-683.

8. Newens AJ, Forster DP, Kay DW, Kirkup W, Bates D, Edwardson J. Clinically diagnosed presenile dementia of the Alzheimer's type in the Northern Health Region: Ascertainment, prevalence, incidence, and survival. Psychology and Medicine 1993;23:631-644.

9. Treves T, Korczyn AD, Zilber N, Kahana E, Leibowitz Y, Alter M, Schoenberg BS. Presenile dementia in Israel. Archives of Neurology 1986;43:26-29.

10. Kokmen E, Beard CM, Offord KP, Kurland LT. Prevalence of medically diagnosed dementia in a defined United States population: Rochester, Minnesota. Neurology 1989;39:773-776.

11. McKhann G, Drachman D, Folstein M, Katzman R, Price D, Stadlan EM. Clinical diagnosis of Alzheimer's disease: Report of the NINCDS-ADRDA work group under the auspices of Department of Health and Human Services Task Force on AD. Neurology 1984;34:939-944.

12. Hofman A, Rocca WA, Brayne C, Breteler MM, Clarke M, Cooper B, Copeland JR, Dartigues JF, da Silva Droux A, Hagnell O. The prevalence of dementia in Europe: A collaborative study of 1980-1990 findings. International Journal of Epidemiology 1991;20:736-748.

13. Ratnavalli E, Brayne C, Dawson K, Hodges JR. The prevalence of frontotemporal dementia. Neurology 2002;58:1615-1621.

14. Bickel H, Burger K, Hampel H, Schreiber Y, Sonntag A, Wiegele B, Forstl H, Kurz A. Prasenile Demenzen in Gedachtnisambulanzen-Konsultationsinzidenz und Krankheitscharakteristika. Nervenarzt 2005; June 15 Epub.

15. Mendez MF, Selwood A, Mastri AR, Frey WH 2d. Pick's disease versus Alzheimer's disease: A comparison of clinical characteristics. Neurology 1993;43:289-292.

16. Mendez MF, Perryman KM. Neuropsychiatric features of frontotemporal dementia. Evaluation of consensus criteria and review. Journal of Neuropsychiatry and Clinical Neuroscience 2002;14:424-429.

17. Passant U, Elfgren C, Englund E, Gustafson L. Psychiatric symptoms and their psychosocial consequences in frontotemporal dementia. Alzheimer Disease and Associated Disordance 2005;16:S15-18.

18. Hodges JR, Davies RR, Xuereb JH, Casey B, Broe M, Bak TH, Kril JJ, Halliday GM. Clinicopathological correlates in frontotemporal dementia. Annals of Neurology 2004;56:399-406.

19. Forman MS, Farmer J, Johnson, JK, et al. Frontotemporal dementia: Clinicopathological correlations. Annals of Neurology 2006;59:952-962.

20. Sampson E, Warren J, Rossor M. Young onset dementia. Postgraduate Medical Journal 2004;80:125-139.

21. Mendez MF, Shapira JS, McMurtray A, Licht E. Behavioral worsening on donepezil in patients with frontotemporal dementia. American Journal of Geriatric Psychiatry (in press).

22. Román GC, Erkinjunit T, Wallin A, Pantoni L, Chui HC. Subcortical ischaemic vascular dementia. Lancet Neurology 2002;1:426-436.

23. Mendez MF, McMurtray A. Frontotemporal dementia-like phenotypes associated with presenilin-1 mutations. Alzheimer Disease and Associated Disordance (in press). 
24. Neary D, Snowden JS, Gustafson L, Passant U, Stuss D, Black S, Freedman M, Kertesz A, Robert PH, Albert M, Boone K, Miller BL, Cummings J, Benson DF. Frontotemporal lobar degeneration: A consensus on clinical diagnostic criteria. Neurology 1998;51:1546-1554.

25. Woodburn K, Johnstone E. Ascertainment of a population of people with early-onset dementia in Lothian, Scotland. International Journal of Geriatric Psychiatry 1999; 14:362-367.

26. Panegyres PK, Davies SR, Connor CF. Early onset dementia. Medical Journal of Australia 2000;173:279-280.

27. Elberling TV, Stokholm J, Hogh P, Waldemar, G. Diagnostic profile of young and middle-aged memory clinic patients. Neurology 2002;59:1259-1262.

28. Yokota O, Sasaki K, Fujisawa Y, Takahashi J, Terada S, Ishihara T, Nakashima H, Kugo A, Ata T, Ishizu H, Kuroda S. Frequency of early and late-onset dementias in a Japanese memory disorders clinic. European Journal of Neurology 2005;12:782-790.

29. Lopez OL, Kuller MD, Becker JT, Jagust WJ, DeKosky ST, Fitzpatrick A, Breitner J, Lyketsos C, Kawas C, Carlson M. Classification of vascular dementia in the Cardiovascular Health Study Cognition Study. Neurology 2005;64:1539-1547.

30. Knopman DS, Parisi JE, Boeve BF, Cha RH, Apaydin J, Salviati A, Edland S, Rocca WA. Vascular dementia in population-based autopsy study. Archives of Neurology 2003;60:569-575.

31. Reed BR, Mungas DM, Kramer JH, Betz BP, Ellis W, Vinters HV, Zarow C, Jagust WJ, Chui HC. Clinical and neuropsychological features in autopsy-defined vascular dementia. Clinical Neuropsychology 2004;18:63-674.

32. Wen et HM, Mok VC, Fan YH, Lam WW, Tang WK, Wong A, Huang RX, Wong KS. Effect of white matter changes on cognitive impairment in patients with lacunar infarcts. Stroke 2004;35:1826-1830.

33. Mendez MF, Ottowitz W, Brown CV, Cummings JL, Perryman KM, Mandelkern MA. Dementia with leukoaraiosis: Clinical differentiation by temporoparietal hypometabolism on ${ }^{18}$ FDG-PET imaging. Dementia and Geriatric Cognition Disordance 1999; 10:518-525.

34. Chui HC, Victoroff J, Margolin D, Jagust W, Shankle R, Katzman R. Criteria for the diagnosis of ischemic vascular dementia proposed by the state of California Alzheimer's Disease Diagnosis and Treatment Centers. Neurology 1992;42:473-480.

35. Kano I, Mori S, Nakajima K, Nakagawa M, Watanabe Y, Kizu O, Yamada K, Sakai Y. Do white matter changes have clinical significance in AD? Gerontology 2004; 50:242-246.

36. Mendez MF, Perryman K, Doss RC. Differences between Alzheimer's disease and vascular dementia on information processing measures. Brain Cognition 1997; 34:301-310.

37. Mendez M, Cherrier M, Perryman K, Pachana N, Miller B, Cummings J. Frontotemporal dementia vs. AD: Differential cognitive features. Neurology 1996;47: 1189-1194.

38. Smith DM, Atkinson RM. Alcoholism and dementia. International Journal of the Addictions 1995; 30: 1843-1869

39. McKeith IG, Perry EK, Perry RH. Report of the second dementia with Lewy body international workshop: Diagnosis and treatment. Consortium on dementia with Lewy bodies. Neurology 1999;53:902-905. 
40. Loring DW, Largen JW. Neuropsychological patterns of presenile and senile dementia of the Alzheimer type. Neuropsychologia 1985;23:351-357.

41. Jacobs D, Sano M, Marder K, Bell K, Bylsma F, Lafleche G, Albert M, Brandt J, Stern Y. Age at onset of Alzheimer's disease: Relation to the pattern of cognitive dysfunction and rate of decline. Neurology 1994;44:1215-1220.

42. Kono K, Kuzuya F, Yamamoto T, Endo H. Comparative study of cerebral ventricular dilation and cognitive function in patients with Alzheimer's disease of early versus late onset. Journal of Geriatric Psychiatry and Neurology 1994;7:39-45.

43. Seltzer B, Sherwin I. A comparison of clinical features in early-and late-onset primary degenerative dementia. One entity or two? Archives of Neurology 1983;40:143-146.

44. Caine D, Hodges JR. Heterogeneity of semantic and visuospatial deficits in early Alzheimer's disease. Neuropsychology 2001;15:155-164.

45. Frisoni GB, Testa C, Sabattoli F, Beltramello A, Soininen H, Laakso MP. Structural correlates of early and late onset Alzheimer's disease: Voxel based morphometric study. Journal of Neurology, Neurosurgery and Psychiatry 2005;76;112-114.

46. Kemp PM, Holmes C, Hoffmann SM, Bolt L, Holmes R, Rowden J, Fleming JS. Alzheimer's disease: Differences in technetium-99m HMPAO SPECT scan findings between early onset and late onset dementia. Journal of Neurology, Neurosurgery, and Psychiatry 2003;74:715-719.

47. Sakamoto S, Ishii K, Sasaki M, Hosaka K, Mori T, Matsui M, Hirono N, Mori E. Differences in cerebral metabolism between early and late onset types of AD.Journal of Neurological Science 2002;200:27-32.

48. Cruts M, Van Broeckhoven C. Presenilin mutations in AD. Human Mutation 1998; 11:183-190.

49. Raux G, Gantier R, Thomas-Anterion C, Boulliat J, Berpillat P, Hannequin D, Brice A, Frebourg T, Campion D. et al. Dementia with prominent frontotemporal features associated with L113P presenilin 1 mutation. Neurology 2000;55:1577-1578.

50. Mendez MF, Chen AK, Shapira SS, Miller BL. Acquired sociopathy in frontotemporal dementia. Dementia and Geriatric Cogntion Disorders 2005;20:99-104.

\section{Direct reprint requests to:}

Mario F. Mendez

Neurobehavior Unit (116AF; Bldg 500,3S)

VA Greater Los Angeles Healthcare

11301 Wilshire Blvd.

Los Angeles, CA 90073

e-mail:mmendez@ucla.edu 